\title{
Metaphor and Education
}

\author{
Analyzing the Role of Cultural Empathy in Teaching Chinese as a Foreign Language
}

\author{
Shuqing $\mathrm{He}$ \\ Department of Humanities \\ Zhejiang University \\ Hangzhou, China
}

\begin{abstract}
Cultural stereotype is a double-edged sword, it can enable students to understand foreign culture in a short time and form a thought of first impression and then generate a negative influence such as rejection and bias against a culture. During the teaching of international Chinese, in order to avoid the negative influence of cultural stereotype, teachers are required to train students' abilities of cultural empathy. In this article, based on studying the influence of cultural stereotype in the teaching of international Chinese, this author raises an opinion of training students' cultural empathy, and show a teaching program of training students' abilities of cultural empathy during the teaching of international Chinese through analyzing the teaching logs and trans-cultural interaction cases of international Chinese teachers at home and abroad.
\end{abstract}

Keywords-cultural stereotype; cultural empathy; international Chinese teaching; teaching design

\section{INTRODUCTION}

Going with the gradual internationalization of Chinese, international Chinese teaching undertaking has made a great progress in China. International Chinese teachers have deeply understood: What international Chinese class teaches are more than phonetics, grammars and characters, it is a culture more. In an international Chinese class, maybe one teacher will teach students from different countries around the world, facing such as situation, international Chinese teachers need to well control the double-edged sword-cultural stereotype. Through discussing the negative and positive influences of cultural stereotype in the teaching of international Chinese, this article raises an idea of training students' abilities of cultural empathy in learning international Chinese. Through analyzing the teaching $\operatorname{logs}$ and trans-cultural interaction cases of international Chinese teachers at home and abroad, this author prepares a teaching program aiming at training students' abilities of cultural empathy in learning international Chinese, which is expected to be referenced by international Chinese teachers at home and abroad.

\section{Cultural Stereotype of ITS INFLUENCE IN THE TEACHING OF INTERNATIONAL CHINESE}

What doest cultural stereotype mean? How do we understand it? What are the influences of cultural stereotype in the teaching of international Chinese teaching?

\section{A. Definition}

The concept stereotype was first raised by Lippmann, an American political critic, in his works Public Opinion released in 1922. In his opinion, the environments where people live, whether natural environment and social environment, are too complicated to experience and understand all people and all things around the world by themselves. In order to save the time, a simplified method for recognition is used: a group of people, nation or race that has the same characteristics are built into a certain image. Cultural stereotype, also called stereotyped image, stereotype or prejudice, spoken simply, refers to a recapitulative view on characteristics of a group of members. During trans-cultural communication, the cultural stereotype is commonly seen, for example, we are often told, French are romantic, Italian are quite passionate, German are very strict and Japanese often bow to others, all of which are reflections of cultural stereotype.

Different scholars define the cultural stereotype differently, Lippmann initially took the stereotype as a negative concept for use, and he thought the stereotype was a wrong and irrational way of thinking. Guan Shijie thinks that the stereotype is a simplified view of a group of members showed to another. Kramsch thought the stereotype is a modularized understanding of other groups and cultures. Fan Jieping thinks that the stereotype is a neutral concept in sociology, mainly referring to the judgment pattern on thinking mode, information, external world and behavior characteristics. The opinion of neutral concept stands for what most social psychologists hold, because they find that the stereotype is a commonly shared cognitive type for human being.

According to the views of scholars on the cultural stereotyped and cases of foreigners' impression on China, we have to think, during the teaching of international Chinese teaching, What are the influences that the cultural stereotype brings to our Chinese class?

\section{B. Influences of Cultural Stereotype in the Teaching of International Chinese Language}

In a word, the cultural stereotype is a double-edged sword during the teaching of international Chinese, which has something positive and also something negative, just like what $\mathrm{Hu}$ Wenzhong said, the beliefs may be positive or negative; generally the word is used with derogatory sense. That is to say, though the cultural stereotype is a neutral word, 
yet it is not a completely neutral one, instead, it has more harm than good.

First, let's see the positive side of cultural stereotype, during the teaching of international Chinese, the positive side of cultural stereotype is that teachers and students who are in the circle of trans-cultural communications can rapidly understand the characteristics of another cultural circle, achieving the goal of teaching activities. For every country around the world has unique cultural tradition and cultural atmosphere of its own, even the folk culture at each place differs in China with a long history and vast lands. It is said that winds differ within ten miles and customs differ within one hundred miles. So facing such a situation, we need to classify the culture, for which, the cultural stereotype is a convenient way for classification. Brislin points out: Don't take stereotype (cultural stereotype) as an abnormal thought; on the contrary, its existence reflects that we have to organize, memorize and get usable information in order to achieve goals and meet needs.

However, seen from the other side, it is true that the existence of cultural stereotype has something negative, for example, the cultural stereotype is often linked to negative attitudes such as prejudice, ethnocentrism, tribalism, ethnic prejudice, religious prejudice, sex prejudice and so on.

During the teaching of international Chinese, the negative influences of cultural stereotype are mostly emerging among international students with different cultures. For the students come from different countries with diverse cultural background, without understanding other cultural background, it is easy to cause misunderstanding and even discrimination. For example $^{\mathbb{1}}$, at an international Chinese class, teacher Wang finds that the students come from Japan, South Korea, Malaysia, Indonesia, USA, Russia and so on. However, after a period of time, he finds that during whether the class activities or after-class communications, it looks that the students only communicate with those who come from the same country or have similar cultural background, and the students are severely rejecting foreigners. Another example, this author ever went to listen to a lecture at an advanced language class at the school of international education of our college, the class them was the first impression on China, one student said, it looked Chinese students were bookworms only, so he disliked Chinese students. Again, if a student rejects the culture of a country, he or she will reject the students from the country, as a result, it will cause troubles to the Chinese teaching in classes, even influencing the normal class teaching.

Samovar summarizes three points for reasons for cultural stereotype, which is, influenced by parents, relatives or friends; impression of self communications; getting from media. Wen Zhengping thinks that the cultural stereotype is formed under environmental factors such as socialization, media and bandwagon effect. After knowing about the influences of cultural stereotype and reasons, we should find feasible solutions against the negative influences of cultural stereotype during the teaching of international Chinese. Then What we should do?

Re-edition of Cases and Analysis of International Chinese Teaching (Modified) pp 218.

\section{TRAINING OF CULTURAL EMPATHY ON STUDENTS DURING THE TEACHING OF INTERNATIONAL CHINESE TEACHING}

We have talked above that we should find a solution against the negative impact of cultural stereotype during the teaching of international Chinese. What is the feasible solution? We need to train students' abilities of cultural empathy in learning international Chinese.

\section{A. Cultural Empathy}

Empathy belongs to aesthetics, which was first used in the Senses of Visual Formation, and the one who transplanted aesthetic concepts to linguistics was Kuno, a Japanese linguistician, currently the aesthetic artistic conception gradually spreads to psychology and trans-cultural communications. The cultural empathy in the trans-cultural communications refers to a psychological experience, emotional shifts and cognition shift during the trans-cultural communications in order to guarantee normal communications among different cultures, namely it is a psychological trend that a person during the communications actively changes the cultural position and surpasses on purpose the restriction of local culture, gets rid of traditional culture deposits, feels and understands foreign cultures, feeling comfortable after surpassing the cultural stereotype of local language and culture and thinking through the mode of another culture. Many scholars and experts ever point out that whether the trans-cultural communication will succeed or not mostly depend on whether the persons could subjectively define subject and object, and then well understand the other people, able to understand and satisfy other characters. During the teaching of international Chinese, what teachers teach shall not only include Chinese and Chinese characters but also the Chinese culture. In order to better the cultural teaching, to train students' abilities of cultural empathy has also become an important part to the teaching of international teaching.

The following is a case for the successful training of cultural stereotype at an international Chinese class ${ }^{(2)}$ :

\section{Case:}

It is a case about an international student on Chinese cultural empathy, and a Korean student writes in a composition:

I always think that Chinese disobey in waiting, liking queue-jump. Afterwards, he was told by Chinese teachers that Chinese think that queue-jump can be selected for simple consultancy without handling procedures; they don't refuse waiting in line. One day, my girlfriend and I went to see a movie, when we were waiting in line; a woman directly went to the front and consulted the seller. After seeing the scene, suddenly what my teachers told me emerged in my mind, and I was just laughing. Now I can understand what that woman had done. If it happened early days, I would think she's impolite, but now I don't. If a consultancy office is set where it is needed, there will be no something like that.

\footnotetext{
(2) Cited from $\mathrm{Zu}$ Xiaomei Chapter VII of Cross-Cultural Communications: Psychology and Attitude for Cross-Border Communications, pp 207-208.
} 
The above case shows, with the cultural empathy owned, international students have changed their mind to Chinese culture, from which, we can understand the importance of training students' abilities of cultural stereotype in learning Chinese. During the teaching of international Chinese, main factor to influence the cultural stereotype of students is the restriction of native culture, lack of corrective values and practice and experience. The mission of international Chinese teachers is to help students overcome the disadvantage and make them form empathy to Chinese culture.

Therefore, after reading many cases and interviewing several international students, this author drafts a teaching program for training international students' abilities of cultural empathy.

\section{B. Training Program for Students' Abilities of Cultural Empathy During the Teaching of International Chinese Language}

- Object: international students at senior class of international Chinese (15-20 students per class)

- Theme: Trans-cultural communication-Impression on China

- Class hour: 3 classes, 45 minutes per class

- Teaching goal: Train students' abilities of cultural stereotype

- Teaching method: direct method, situational method, audio-lingual method, audio-visual method, total physical response method, communicative method

- Teaching points: Training students' abilities of cultural stereotype

- Teaching background: in an international Chinese class, the students mostly come from different countries, due to the restriction of local culture and the influence of inadequate experience in China, it's unavoidable that the students will get some negative impression on China, such as Chinese characters are too difficult to write, I'd better write Pinyin as possibly as I can, China is poor and closed, they have no good culture worthy of learning, Chinese like talking about relations, I talk with classmates more that I do with teachers, thus the teacher will give me a lower score and so on". The negative cultural stereotype has not only lowered students' learning efficiency but also influenced the students' interest to learn Chinese culture and impression on China. So facing such a situation, to train students' abilities of cultural stereotype has become an urgent task for international Chinese teachers to solve.

- $\quad$ Teaching

\section{1) Class 1}

a) Teacher raise questions: What's your impression on China, negative? Positive? Specify b) Group discussion: 3-4 persons per group. Discuss their impressions on China respectively, make records those positive and negative, totaling 15-20 minutes.

c) Each group appoints a representative to make a speech: state what they think positive or negative, and other students can raise problems at any time, totaling 15-20 minutes.

d) Teachers make records and conclusions: Teachers will record what international think it negative during the discussion such as Chinese dislike waiting in line, Chinese students are mostly bookworms, Chinese like talking about relations, Chinese characters are too difficult to write and so on.

e) Task assignments: Teachers will distribute the recorded negative impressions on China to each group, asking them to look up relevant data, record information and give cases to specify whey the phenomena happen, find reasons and make PPT. With the PPT completed, students will send representatives to state what they think, supported by PPT.

2) Class 2

After completion of assignments in class 1, the students can go to library, reference rooms or interview teachers or other students.

\section{3) Class 3}

a) PPT show: Each group shall show what they have collected, totaling 15-20 minutes.

b) Teacher-student discussion: Teachers instruct students to own inclusive understanding, then train their abilities of stereotype, totaling 10 minutes.

c) Movie \& TV culture teaching: teachers may make full use of domestic excellent movies resources to create students' perceptual knowledge about China, such as 5000 Years of Chinese Characters, A Bite of China, Chinese Calligraphy in 5000 Years, Daming Palace and so on, which can be displayed in class till minutes before end, and the rest of moves are suggested for appreciation by students after class.

d) Teaching feedback: Teachers make a questionnaire with no names exposed to check how the students' abilities of empathy work. The contents shall be the acceptability of negative impression on China that is discussed in class.

\section{CONCLUSION}

During the teaching of international Chinese, teachers shall train students to shift from negative cultural stereotype to cultural empathy, student will undergo fluctuation in emotion and recognition and teachers also undergo the same in teaching. With the abilities of cultural empathy, international Chinese students will feel much easier to understand foreign culture and become inclusive and understandable for whether the Chinese culture learned or classmates in other cultural circles. These will do good to their learning efficiency and getting well along with others. To make good use of the double-edged sword-cultural stereotype is also an exercise to skills of international Chinese teachers. Whether the students are trained of empathy through 
movie and TV transmissions or group discussion and so on, the purpose of international Chinese teachers is to make the cultural stereotype become bitter for students but sweet for teachers, so that the international Chinese class will become much more efficient and harmonious.

\section{REFERENCES}

[1] $\mathrm{Zu}$ Xiaomei, Cross-Cultural Communications [M]. Beijing: Foreign Language Teaching and Research Press, 2015.192-193, 207-208.

[2] Zhu Yong, Cases and Analysis of International Chinese Teaching [M]: Higher Education Press, 2016

[3] Confucius Institute Headquarters (Hanban). Analysis of Examination Outline of Certificate Examination for Teachers of Chinese to Speakers of Other Languages [M].Beijing: People's Education Press, 2015.9.

[4] Wang Jianqin, Studies on Learning a Second Language [M]. Beijing: The Commercial Press, Aug 2009, Issue 1.

[5] Chen Qi, Liu Rude, Modern Educational Psychology [M] Beijing: Beijing Normal University Publishing House, 2007.3.

[6] Shen Qunli, Base Patters and Characteristics of Teaching Design [J]. Journal of Guangzhou University (Social Science Edition), Jul 2006, Issue No.7 of Vol.5

[7] Wu Yanping, Training Students' Abilities of Cultural Empathy During Teaching of College English [J] Journal of Tianjin Radio and Television University, Jun 2011, Issue No.2 of Vol. 15.

[8] Luo Hong, Liu Zhen'ai, Reflection of Cultural Empathy Theory [J]. The Border Economy and Culture, Issue No.9, 2005, Period 21.

[9] Yu Xiaoxia, Cultural Empathy in Communications [J] Journal of Zhejiang Education Institute, Mar 2004, Issue No.2.

[10] Zheng Yi, Liu Shuhua, Training of Cultural Empathy in Cross-Cultural Communication [J]. Issue No.4, 2010, Issue No.4 of Vol. 12. 